\title{
Current Status and Future Perspective of Coronavirus Disease 2019: a Review
}

\author{
Slavenka Janković ${ }^{1}$
}

\section{Abstract}

A novel infectious disease named coronavirus disease-2019 (COVID-19) first emerged in Wuhan, China, in December 2019 and rapidly spread worldwide. In March 2020 the World Health Organization declared a global pandemic which is the worst global public health crisis in over 100 years. On 14 June 2020, almost eight million confirmed cases of COVID-19 and more than 430,000 deaths globally were reported. Over 200 countries have been affected so far. COVID-19 is caused by the severe acute respiratory syndrome coronavirus 2 (SARS-CoV-2). In the absence of specific therapy and vaccine, effective infection control intervention, particularly self-hygiene and social distancing, is the only way to prevent the spread of SARS-CoV-2. The lessons learned from this pandemic will be useful for successful management of the second wave of COVID-19 which is expected in autumn or winter.

Key words: SARS-CoV-2, COVID-19, coronavirus, pandemic, world, epidemiology.
(1) Institute of Epidemiology, Faculty of Medicine, University of Belgrade, Belgrade, Serbia.

Correspondence:

SLAVENKA JANKOVIĆ

E: slavenkaj@gmail.com

M: +381637189940

\section{ARTICLE INFO}

Received: 15 June 2020

Revision received: 21 June 2020 Accepted: 23 June 2020

\section{Introduction}

Human infections with zoonotic coronaviruses (CoVs) are emerging public health problems worldwide. In the last two decades, two major coronavirus outbreaks have occurred, the severe acute respiratory syndrome (SARS) in 2002, ${ }^{1}$ and the Middle East respiratory syndrome (MERS) in $2012 .^{2}$

The recent outbreak of novel coronavirus disease-2019 (COVID-19), caused by the severe acute respiratory syndrome coronavirus 2 (SARSCoV-2), emerged in Wuhan, China, in December $2019^{3}$ and rapidly spread throughout the world. At the end of January 2020, the World Health Organization (WHO) declared the novel coronavirus epidemic a public health threat of international importance. ${ }^{4}$ On 11 March 2020, the WHO declared the coronavirus outbreak a pandemic. ${ }^{5}$

\section{Causative agent}

COVID-19 is caused by the SARS-CoV-2, a novel betacoronavirus.

CoVs are RNA viruses that infect primarily birds and mammals. In humans, CoVs are mainly associated with upper respiratory tract infections, but can cause severe diseases. However, some CoVs can be transmitted from animals to humans causing outbreaks. The human SARS-CoV, aetiologic agent of SARS, originated from bats in China, ${ }^{6}$ and MERS-CoV, etiologic agent of MERS, originated from camels or bats in the Middle East. ${ }^{7}$

Bats are most likely the natural reservoir of SARS-CoV-2, while the intermediate animal host between bets and humans is not yet known. ${ }^{8}$ Also, it is not known whether this virus in a future will adapt fully to humans and circulate within them without an animal reservoir or intermediate host. ${ }^{9}$ SARS-CoV-2 has similar charac-

Copyright $\odot 2020$ Janković. This is an open access article distributed under the Creative Commons Attribution License (CC BY), which permits unrestricted use, distribution, and reproduction in any medium, provided the original work is properly cited. This article should be cited as follows: Janković S. Current status and future perspective of coronavirus disease 2019: a review. Scr Med 2020;51(2):101-9. 
teristics with SARS-CoV. It is confirmed that both viruses use the same cell entry receptor - angiotensin-converting enzyme 2 (ACE2).$^{10}$ However, SARS-CoV-2 is more transmissible, but less pathogenic than SARS-CoV.

There is evidence that SARS-CoV can remain infectious on inanimate surfaces for several days and that surface disinfection with broad-spectrum disinfectants of proven antiviral activity (eg $70 \%$ ethanol) significantly reduces its infectivity after short exposure time. Researchers expect a similar effect for the SARS-CoV-2. ${ }^{11}$

\section{Epidemiology}

\section{Geographic distribution}

At the time of writing (14 June 2020), the SARSCoV-2 continues its global spread, with almost eight million confirmed cases and more than 430,000 deaths worldwide. ${ }^{12}$

Cumulative cases and deaths of COVID-19 across the world from 1 January to 13 June 2020, are presented in Figure 1.

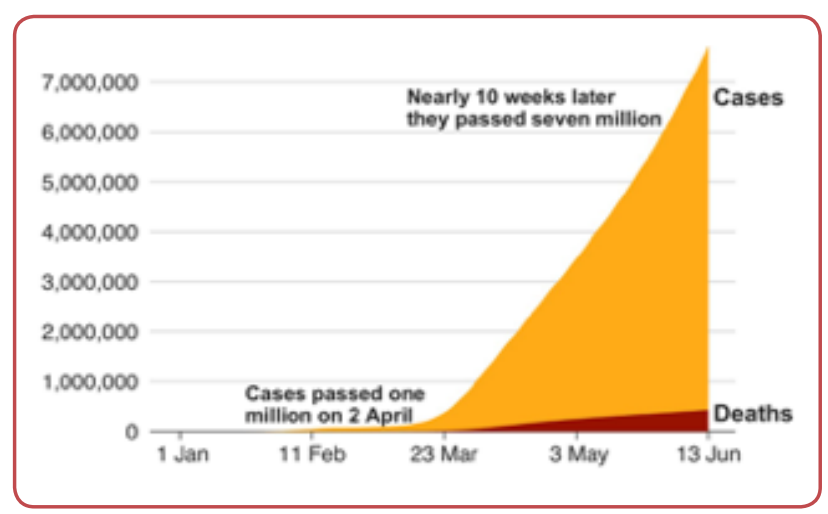

Figure 1: Global coronavirus cases and deaths

Source: Johns Hopkins University, National Health Agencies. $B B C^{12}$

All continents, except Antarctica, are affected by SARS-CoV-2. Total confirmed COVID-19 cases and deaths across continents, on 14 June 2020, are presented in Table 1.

Until now, COVID-19 cases have been confirmed in almost all countries worldwide. ${ }^{13}$

Total confirmed COVID-19 cases and deaths in 20 most affected countries in the world are presented in Table 2.
Table 1: Total confirmed COVID-19 cases and deaths worldwide on 14 June 2020, by continent

\begin{tabular}{l|r|r}
\hline Continent & Total cases & Total deaths \\
\hline Asia & $1,617,030$ & 40,246 \\
\hdashline Africa & 236,929 & 6,306 \\
\hline Europe & $2,205,339$ & 182,855 \\
\hline Oceania & 8,931 & 124 \\
\hline North America & $2,469,848$ & 144,789 \\
\hline South America & $1,402,112$ & 59,604 \\
\hline Total & $\mathbf{7 , 9 4 0 , 1 8 9}$ & $\mathbf{4 3 3 , 9 2 4}$ \\
\hline Source: Worldometer. COVID-19 Coronavirus pandemic. & \\
\hline
\end{tabular}

Many factors make international comparison difficult: different ways of recording COVID-19 cases and deaths, different population sizes, different percentages of the elderly in different countries, different density of populations, as well as different stages of a pandemic in any single country.

It is worth noting that the total number of people infected with SARS-CoV-2 is unknown since it depends on the number of people who have been tested.

\section{Age and sex}

People of all ages and both sexes can be affected by SARS CoV-2. Middle-aged adults and the elderly are most commonly affected, while children are rarely affected. The course of the disease is severe in the elderly. ${ }^{14}$ Based on the recently reported data, COVID-19 affects men and women almost equally. However, compared to women, men have more severe disease and a higher risk of death, potentially due to sex-based immunological or gendered differences. ${ }^{15-18}$

\section{Transmission}

SARS-CoV-like viruses are sought to have been introduced into the human population from wildlife hosts. Since the first cases of the COVID-19 disease in Wuhan, China, were linked to direct exposure to seafood market that sold live animals, it was thought that the main mode of transmission was animal to human spread. ${ }^{19}$ However, with the increase in the number of infected persons, it became clear that the main route of transmission is person-to-person spread, by direct contact and respiratory droplets. ${ }^{20}$

It is evident that SARS-CoV-2 is capable of person-to-person transmission with a secondary attack rate of 3 to $10 \%{ }^{8}$ It is worth noting that the expected number of secondary cases of COVID-19 may change as further information becomes avail- 
Table 2: Total confirmed COVID-19 cases and deaths worldwide on June 14, 2020, by country

\begin{tabular}{|c|c|c|c|c|c|c|}
\hline Continent & Total cases & Total deaths & $\begin{array}{r}\text { Total cases/ } \\
1 \mathrm{M} \text { popul. }\end{array}$ & $\begin{array}{r}\text { Deaths/ } \\
\text { 1M popul. }\end{array}$ & Total tests & $\begin{array}{r}\text { Tests/ } \\
1 \mathrm{M} \text { population }\end{array}$ \\
\hline USA & $2,152,112$ & 117,676 & 6,504 & 356 & $24,562,632$ & 74,227 \\
\hline Brazil & 852,785 & 42,837 & 4,013 & 202 & $1,499,041$ & 7,055 \\
\hline Russia & 528,964 & 6,948 & 3,625 & 48 & $14,880,172$ & 101,967 \\
\hline India & 332,901 & 9,520 & 241 & 7 & $5,658,614$ & 4,102 \\
\hline UK & 295,889 & 41,698 & 4,360 & 614 & $6,772,602$ & 99,789 \\
\hline Spain & 291,008 & 27,136 & 6,224 & 580 & $4,465,338$ & 95,507 \\
\hline Italy & 236,989 & 34,345 & 3,919 & 568 & $4,620,718$ & 76,419 \\
\hline Peru & 225,132 & 6,498 & 6,833 & 197 & $1,338,477$ & 40,623 \\
\hline Germany & 187,621 & 8,868 & 2,240 & 106 & $4,694,147$ & 56,035 \\
\hline Iran & 187,427 & 8,837 & 2,233 & 105 & $1,244,074$ & 14,821 \\
\hline Turkey & 178,239 & 4,807 & 2,114 & 57 & $2,632,171$ & 31,226 \\
\hline Chile & 174,293 & 3,323 & 9,121 & 174 & 840,150 & 43,968 \\
\hline France & 156,813 & 29,398 & 2,403 & 450 & $1,384,633$ & 21,215 \\
\hline Mexico & 142,690 & 16,872 & 1,107 & 131 & 401,755 & 3,118 \\
\hline Pakistan & 139,230 & 2,632 & 631 & 12 & 868,565 & 3,936 \\
\hline Saudi Arabia & 127,541 & 972 & 3,666 & 28 & $1,106,398$ & 31,806 \\
\hline Canada & 98,735 & 8,146 & 2,617 & 216 & $2,113,924$ & 56,033 \\
\hline Bangladesh & 87,520 & 1,171 & 532 & 7 & 504,465 & 3,065 \\
\hline China & 83,132 & 4,634 & 58 & 3 & & \\
\hline Qatar & 79,602 & 73 & 28,350 & 26 & 290,714 & 103,538 \\
\hline
\end{tabular}

M: million Source: Worldometer. COVID-19 Coronavirus pandemic. ${ }^{13}$

able. ${ }^{21}$ Close contact between persons is necessary. The spread of virus occurs primarily where there is close contact - in the family, hospitals ${ }^{22}$ and long-term care facilities. ${ }^{23}$ Reported clusters of cases after social or work gatherings also suggest the risk of transmission through close contact.

Symptomatic patients are the most important source of SARS-CoV-2 spread. Transmission from infected persons during the incubation period has been documented. ${ }^{24}$ Although one study reported that coronavirus may have been transmitted by the asymptomatic carrier, ${ }^{25}$ the relative contribution of asymptomatic carriage or transmission to the overall disease burden remains unclear. ${ }^{21}$ Since the SARS-CoV-2 is detected in newborns, they might play a role in transmission. ${ }^{26}$

Contaminated surfaces may be a source of infection if susceptible persons touch these surfaces and then transfer the virus to eyes, nose or mouth. The frequency and relative importance of this type of transmission remain unclear. ${ }^{14}$ The risk of transmission by contaminated paper (eg paper documents and paper money) is low. ${ }^{27}$

Till now, airborne spread, faecal-oral transmission, and bloodborne transmission have not been documented. $^{28}$
The period of communicability is not yet completely understood. ${ }^{29}$ It appears that SARS-CoV-2 can be transmitted before the development of symptoms and throughout the course of illness. Some studies have suggested transmission as early as five days before symptom onset. Latest time of communicability is unknown at this time. ${ }^{30}$

Initial estimates suggested that the basic reproductive number - Ro (the mean number of newly infected from an infected person in a susceptible population) for the SARS-CoV-2 was $2.7 .{ }^{31}$ However, Sanche et al. ${ }^{32}$ calculated much higher Ro (5.7) in the same population. Besides, some evidence indicates that several COVID-19 patients were recognised as "super-spreaders" because of the high number of persons secondarily infected. SARS$\mathrm{CoV}-2$ is more transmissible than severe influenza pandemic viruses in the past. ${ }^{33}$

\section{Immunity and risk of reinfection}

Antibodies to the SARS-CoV-2 are induced in people who have become infected. However, it is unknown how long any protective effect will last. Till now, there is no evidence that people who have recovered from COVID-19 are protected from reinfection. ${ }^{14}$ It is also not known yet whether mild or asymptomatic cases will develop antibodies. 


\section{Clinical features}

\section{Incubation period}

The incubation period for COVID-19 is estimated to be between 2 and 14 days (median 5-6 days), with isolated reports of a longer period..$^{14}$ Some persons can be contagious during incubation. Therefore, transmission from a pre-symptomatic case can occur before the symptom onset. ${ }^{29}$

\section{Clinical manifestation}

Early signs and symptoms of COVID-19 are consistent with influenza-like illness, with a spectrum of disease ranging from milder presentation to severe respiratory illness. Pneumonia is the most frequent serious manifestation of infection. Most patients experience fever, cough, fatigue, anorexia, shortness of breath, and myalgia. Other symptoms, like sore throat, nasal congestion, headache, diarrhoea, nausea, vomiting and smell or taste disorders can also be present. ${ }^{22,34}$

A serious complication in critically ill patients is acute respiratory distress syndrome (ARDS) which can occur suddenly. Other complications include arrhythmia, shock, acute cardiac injury and multiple organ dysfunction syndrome (MODS). ${ }^{22,34}$ Most patients who required hospitalisation were older persons with underlining comorbidities. About $20 \%$ of hospitalised patients required admission to the intensive care unit for critical management. Cases can become severe quickly, progressing to ARDS or MODS, leading to death. ${ }^{35-37}$

Symptomatic infections in children are rare and usually mild. ${ }^{26}$ Asymptomatic infections are common, but the precise frequency is unknown. ${ }^{14}$

\section{Risk factors for severe illness}

Based on the literature review, elderly, people with underlying diseases (cardiovascular diseases, diabetes, hypertension, chronic lung disease, cancer, chronic kidney disease, severe obesity, etc) and those immunocompromised are at higher risk for severe form of COVID-1938, 39 and have a higher risk of dying from this disease ${ }^{40}$ Healthcare workers and patients in the hospital setting have a higher risk of becoming infected with SARS-CoV-2 than people in the community. ${ }^{41}$

\section{Laboratory and imaging findings}

Laboratory findings in patients with COVID-19 include lymphopenia and elevated levels of aminotransaminases, dehydrogenase and markers of inflammation such as C-reactive protein and erythrocyte sedimentation rate. ${ }^{34}$

Pneumonia caused by SARS-CoV-2 manifests with a specific chest computed tomography imaging, even in asymptomatic patients. ${ }^{42}$

\section{Case fatality rates and recovery}

Case fatality rates from COVID-19 vary widely between countries from $0.2 \%$ in Germany to $7.7 \%$ in Italy. ${ }^{43}$ The overall case fatality rate is $2.3 \%{ }^{14}$ Recovery time for mild infections is two weeks, while for a severe disease it lasts three to six weeks. $^{44}$

\section{Diagnosis}

Diagnosis of COVID-19 is based on laboratory confirmation of SARS-CoV-2, specific clinical and imaging criteria compatible with COVID-19 and epidemiological criteria.

According to the latest case definition for COVID-19, as of 29 May 2020:

- Confirmed case of COVID-19 is any person meeting the laboratory criteria (detection of SARS-CoV-2 RNA in a clinical specimen);

- Probable case of COVID-19 is any person meeting the clinical criteria (at least one of the following symptoms: cough, fever, shortness of breath, sudden onset of anosmia, ageusia or dysgeusia) and epidemiological criteria (close contact with a confirmed COVID-19 case in the 14 days prior the onset of symptoms) or any person meeting the diagnostic imaging criteria (radiological evidence of lesions compatible with COVID-19); and

- Possible case of COVID-19 is any person meeting the clinical criteria mentioned above. ${ }^{45}$

\section{Diagnostic tests for SARS-CoV-2}

Two types of diagnostic tests for SARS-CoV-2 infections are available: molecular tests to detect viral RNA and serological tests to detect IgG and IgM antibodies.

\section{Molecular tests}

The main technique for diagnosis of current infection with SARS-CoV-2 is viral RNA detection by reverse transcription-polymerase chain reaction (RT-PCR) during the first or second week 
of disease. The WHO recommends collection of nasopharyngeal or oropharyngeal specimens for testing and, if clinical symptoms and signs remain and tests are negative, collection of specimens from the lower respiratory tract (sputum or bronchoalveolar lavage in a ventilated patient) when available. ${ }^{46,47}$

The test reliability depends on the type of collected specimens, sampling techniques, extraction and detection of viral RNA, and the quality of diagnostic reagents. Due to the low sensitivity of real-time RT-PCR assay, the persistence of clinical symptoms and signs where tests are negative requires the repetition of testing. ${ }^{48}$

\section{Serological tests}

Serological tests detect antibodies to the SARSCoV-2 in blood. They are particularly useful for monitoring and responding to COVID-19 pandemic through detection of asymptomatic or mild cases of infection in the population. ${ }^{49}$

The earliest and most sensitive serological marker is level of total antibodies. IgM and IgG antibodies may be positive early after the symptom onset, with higher levels occurring in the second and third week of disease. After that IgM antibodies gradually decline, while IgG antibodies start to increase and may persist over seven weeks. ${ }^{50}$

It is not known yet whether antibodies to SARS$\mathrm{CoV}-2$ can protect against reinfection and how long that protection might last. Scientists worldwide are doing studies to answer those questions. ${ }^{51}$

Rapid immunodiagnostic tests can only indicate the presence or absence of SARS-CoV-2 antibodies. However, they need further validation to determine their accuracy and reliability. In addition, antibodies to SARS-CoV-2 may have cross-reactivity with antibodies to other CoVs. ${ }^{52}$

\section{Prevention and control}

\section{Global public health measures}

The WHO advises all countries to take action to detect COVID-19 infection and prevent spread, emphasizing following priorities for countries: protection of health workers and those at highest risk of severe disease (eg elderly and people with comorbidities) and supporting vulnerable countries in containing infection. ${ }^{44}$
The WHO recommends screening for international travellers from areas with ongoing outbreak of COVID-19 to identify particularly persons with fever and cough and those with high-risk exposure..$^{53}$

Other public health measures including social distancing efforts and stay-at-home decrees, aggressive contact tracing ("test, test, test...") and quarantine, restricting and policies on face masks or coverings in public, have been variably employed in different countries. Despite affording only limited evidence, all studies found quarantine to be important for controlling the spread of severe coronavirus disease. Decision makers worldwide should monitor the outbreak situation all the time and the impact of the measures they implement. $^{54}$

\section{Preventing exposure in the community}

Currently, the best prevention is to avoid being exposed to the SARS-CoV-2. People should be suggested to practice social (spatial) distancing ${ }^{55}$ by staying at home and maintaining two metres distance from others in the community. In particular, individuals should avoid crowds and close contact with potentially ill people.

The measures that are recommended to reduce transmission of virus are:

- Proper hand washing, especially after touching surfaces in public places or use of alcohol-based hand sanitiser when hand washing is not available.

- Respiratory hygiene (covering the cough or sneeze with disposable tissues, and hand washing).

- Avoiding touching the eyes, nose, and mouth.

- Cleaning and disinfecting surfaces that are touched often (at home, workplace, school).

The WHO does not recommend wearing a medical mask in the community for those without respiratory symptoms. ${ }^{56}$ Recommendations on use of masks by healthy people in the community vary by country. ${ }^{57}$

\section{Management of asymptomatic persons with potential exposure}

For people returning from international travel and those who have had close contact with a patient with suspected or confirmed COVID-19, the following measures are suggested: ${ }^{58,59}$

- Self-quarantine at home for 14 days following the last exposure;

- Avoiding contact with persons at high risk for 
severe illness (eg the elderly and those with serious medical conditions);

- Temperature checks and monitoring for symptoms such as fever, cough, or dyspnoea. If individuals develop such symptoms, they should continue to stay at home isolated from other household members and contact their physicians.

Some institutions are testing asymptomatic persons after an exposure. However, a negative test does not rule out subsequent development of infection with SARS-CoV-2 and therefore infection control precautions should be continued for the duration of the incubation period, despite a negative result.

\section{Management of the immediate environment} There is evidence that SARS-CoV-2 may remain viable for hours to several days on different surfaces. Frequent touching of contaminated surfaces in public areas is therefore a potential route of SARS-CoV-2 transmission. Cleaning of visibly dirty surfaces with water and detergents followed by disinfection with $0.1 \%$ sodium hypochlorite, or $62-71 \%$ ethyl alcohol or $0.5 \%$ hydrogen peroxide, reduces the virus infectivity. ${ }^{11}$

\section{Infection control in the healthcare setting}

Infection control measures to reduce spread of COVID-19 in a healthcare setting are warranted. They include universal source control, early identification and immediate isolation of patients with suspected disease, use of personal protective equipment (eg N95 or other respirators or FFP3 masks, goggles or a face shield, gloves and gowns) and environmental disinfection. ${ }^{60}$

Healthcare workers should monitor themselves for symptoms of COVID-19 and stay home if they are ill; wear a medical mask or respirator while in the hospital setting and performed hand washing immediately after any contact with the face covering.

Patients should be screened for clinical manifestations consistent with COVID-19 before entry into a hospital. In some institutions, when N95 respirators are not available for routine use, patients with COVID-19 are asked to wear a medical mask during face-to-face contact with healthcare workers, even when they are in their room, to lower their risk of transmitting infection. When this is done, healthcare workers must still use appropriate personal protective equipment, as described above. In patients with COVID-19, aerosol-generating procedures should be avoided when possible to reduce the potential risk of transmission to health care workers. ${ }^{60}$

\section{Herd immunity}

In addition to public health measures mentioned above, development of herd immunity could protect against COVID-19. However, data on the immune response to COVID-19 are lacking. ${ }^{61}$ It is still unknown how much of the population has been infected. Results from a few serological studies suggest that a relatively small part of the population has been infected (5\% of the Spain's population and $4.4 \%$ of the French population). A household survey conducted in England found that only $0.3 \%$ of the population is currently infected with the virus. ${ }^{62}$ Given the transmissibility of SARS-CoV-2, around $65 \%$ of the population might need to be immune to reach a threshold of herd immunity to end the pandemic ${ }^{63}$ and this will take time. We also do not know how long the post immunity lasts - a few months or several years.

\section{Vaccines - what do we know so far?}

According to WHO, 83 potential COVID-19 candidate vaccines are being assessed, of whom seven have been approved for human testing in clinical trials. ${ }^{64}$ Three approved candidate vaccines are being tested in China. Other vaccine candidates are testing in the UK (one), in the USA (two), and in Germany (one that has been approved but is yet to start). ${ }^{64}$ Although clinical trials have begun, the medical community and the public will have to wait. The proposed time frame for the development of an effective vaccine is at least 12 to 18 months.

\section{Post-exposure prophylaxis}

Based on experiences with post-exposure prophylaxis (PEP) with antimicrobial drugs of other infections, clinical trials are also being conducted to evaluate the safety and efficacy of PEP against COVID-19. ${ }^{65}$

\section{Management of patients}

Patients with mild COVID-19 disease must be isolated at a designated COVID-19 health or community facility or at home (self-isolation). WHO recommends symptomatic treatment and monitoring for clinical worsening, which should prompt hospitalisation. ${ }^{46}$ Patients with suspected or confirmed moderate COVID-19 (pneumonia) should be isolated in hospitals. ${ }^{46}$ 
Management of patients with ARDS depends on its severity. In patients with COVID-19 with mild ARDS non-invasive ventilation may be used. Patients with severe ARDS need intubation and invasive mechanical ventilation. ${ }^{46}$ In case the disease results in MODS, therapy to support the functions of the organs is required. ${ }^{43}$

Clinical care of suspected patients must focus on early recognition, prompt separation and implementation of necessary prevention and control measures. ${ }^{66,67}$

There is no approved specific treatment for COVID-19.68, 69 The recommendations for using antiviral drugs to treat COVID-19 have been recently revised by the US FDA. Remdesivir is recommended for use only in hospitalised adults with severe disease, while chloroquine and hydroxychloroquine, due to their potential for toxicity, are recommended only in clinical trials. ${ }^{70}$

Development and evaluation of drugs and their combination to treat COVID-19 will take several years. ${ }^{71}$ The multinational trial to further evaluate remdesivir, chloroquine and lopinavir-ritonavir has already launched by the WHO. ${ }^{14}$ Convalescent plasma, collected from donors who have recovered from COVID-19, might be useful in treatment of COVID-19 patients. However, randomised controlled trials are necessary to confirm this. ${ }^{72}$

\section{Future perspectives}

Scientists worldwide agree that the global COVID-19 pandemic could have several different endings. The first scenario may be COVID-19 spontaneously disappearing, as it happened with SARS in 2003. The second scenario is that SARS-CoV-2 may continue to sporadically appear over many years with the occasional outbreak as MERS has done. The third, most likely scenario, is that COVID-19, like the 1918 Spanish influenza, may take root in populations worldwide with Covid-19 outbreaks through the end of $2022 .{ }^{73,74}$ If an effective vaccine does not appear during that time, SARS-CoV-2 will continue to circulate with important activity in human population until at least half of the population has been infected..$^{73}$

\section{Conclusion}

COVID-19 is a novel coronavirus disease that has been declared in March 2020 as a pandemic. It is rapidly spreading throughout the globe, infecting almost eight million people and killing more than 430,000 . People of all ages and both sexes can be affected. The disease is severe in elderly and those with comorbidities. To date, vaccine and specific treatment are lacking. Currently, effective infection control intervention, particularly self-hygiene and social distancing, is the only way to prevent the spread of SARSCoV-2.

When the pandemic wanes, it will be possible to assess its impact on the health, economy and social life. The lessons learned from this worst global public health crisis in the last 100 years, especially in terms of international public health, will be useful for successful management of the second wave of COVID-19 which is expected in autumn or winter or any future similar pandemics. Governments across the world will have to balance the needs of the economy and social life with suppressing the spread of the virus.

\section{Acknowledgements}

None.

\section{Conflict of interest}

None.

\section{References}

1. Zhong NS, Zheng BJ, Li YM, Poon LLM, Xie ZH, Chan KH et al. Epidemiology and cause of severe acute respiratory syndrome (SARS) in Guangdong, People's Republic of China in February 2003. Lancet 2003;362:1353-8.

2. Nassar MS, Bakhrebah MA, Meo SA, Alsuabeyl MS, Zaher WA. Middle East Respiratory Syndrome Coronavirus (MERS-CoV) infection: epidemiology, pathogenesis and clinical characteristics. Eur Rev Med Pharmacol Sci 2018;22:4956-61.

3. Huang C, Wang Y, Li X, Ren L, Zhao J, Hu Y, et al. Clinical features of patients infected with 2019 novel coronavirus in Wuhan, China. Lancet 2020;395:497-506. 
4. World Health Organisation. Novel Coronavirus (2019nCoV). Situation report - 11. Geneva, WHO, 31 January 2020. Available at: https://www.who.int/emergencies/ diseases/novel-coronavirus-2019/situation-reports/ (accessed 14 June 2020).

5. World Health Organization. Coronavirus disease 2019 (COVID-19). Situation report - 51. Geneva: WHO, March 11, 2020. Available at: https://www.who.int/emergencies/diseases/novel-coronavirus-2019/situation-reports/ (accessed 14 June 2020).

6. Li W, Shi Z, Yu M, Ren W, Smith C, Epstein JH, et al. Bats are natural reservoirs of SARS-like coronaviruses. Science 2005;310:676-9.

7. Corman VM, Ithete NL, Richards LR, Schoeman MC, Preiser W, Drosten C, et al. Rooting the phylogenetic tree of middle East respiratory syndrome coronavirus by characterization of a conspecific virus from an African bat. J Virol 2014;88:11297-303.

8. World Health Organization. Report of the WHO-China joint mission on coronavirus disease 2019 (COVID-2019). Geneva: WHO, 16-24 February 2020. Available at: http://www.who.int/docs/default-source/ coronaviruse/who-china-joint-mission-on-covid-19-final-report.pdf (accessed 13 June 2020).

9. Ye ZW, Yuan S, Yuen KS, Fung SY, Chan CP, Jin DY. Zoonotic origins of human coronaviruses. Int J Biol Sci 2020;16:1686-97.

10. Li H, Liu SM, Yu XH, Tang SL, Tang CK. Coronavirus disease 2019 (COVID-19): current status and future perspectives. Int J Antimicrob Agents 2020;105951. doi:10.1016/j.ijantimicag.2020.105951

11. Kampf G, Todt D, Pfaender S, Steinmann E. Persistence of coronaviruses on inanimate surfaces and their inactivation with biocidal agents. J Hosp Infect 2020;104:246-51.

12. BBC news. Coronavirus pandemic: tracking the global outbreak. Available at: https://www.bbc.com/news/ world-51235105 (accessed June 14, 2020).

13. Worldometer. COVID-19 Coronavirus pandemic. Available at: https://www.worldometers.info/coronavirus/ (accessed 14 June 2020).

14. McIntosh K. Coronavirus disease 2019 (COVID-19): Epidemiology, virology, clinical features, diagnosis, and prevention. Available at: https://www.uptodate.com/ contents/coronavirus-disease-2019-covid-19-epidemiology-virology-clinical-features-diagnosis-and-prevention\#H3174740477 (accessed June 13, 2020).

15. The Novel Coronavirus Pneumonia Emergency Response Epidemiology Team. The epidemiological characteristics of an outbreak of 2019 novel coronavirus disease (COVD-19) China CDC Weekly. 2020;2:113-22.

16. Wenham C, Smith J, Morgan R, Gender and COVID-19 Working Group. COVID-19: the gendered impacts of the outbreak. Lancet 2020;395:846-8.

17. Chen N, Zhou M, Dong X. Epidemiological and clinical characteristics of 99 cases of 2019 novel coronavirus pneumonia in Wuhan, China: a descriptive study. Lancet. 2020;395:507-13.

18. Mantovani A, Dalbeni A, Beatrice G. Coronavirus disease 2019 (COVID-19): we don't leave women alone. Int J Public Health 2020;65:235-6.

19. Lu H, Stratton CW, Tang YW. Outbreak of pneumonia of unknown etiology in Wuhan, China: The mystery and the miracle. J Med Virol 2020;92:401-2.

20. Chan JF, Yuan S, Kok KH, To KK, Chu H, Yang J, et al. A familial cluster of pneumonia associated with the 2019 novel coronavirus indicating person-to-person transmission: a study of a family cluster. Lancet 2020;395:514-23.

21. Lake MA. What we know so far: COVID-19 current clinical knowledge and research. Clin Med (Lond) 2020;20:124-7.

22. Wang D, Hu B, Hu C, Zhu F, Liu X, Zhang J, et al. Clinical characteristics of 138 hospitalized patients with 2019 novel coronavirus-infected pneumonia in Wuhan, China. JAMA 2020;e201585. doi:10.1001/jama.2020.1585

23. McMichael TM, Clark S, Pogosjans S, Kay M, Lewis J, Baer A, et al. COVID-19 in a long-term care facility King County, Washington, February 27-March 9, 2020.
MMWR Morb Mortal Wkly Rep 2020;69:339-42.

24. Yu P, Zhu J, Zhang Z, Han Y, Huang L. A familial cluster of infection associated with the 2019 novel coronavirus indicating potential person-to-person transmission during the incubation period. J Infect Dis 2020;jiaa077. doi:10.1093/infdis/jiaa077.

25. Bai Y, Yao L, Wei T, Tian F, Jin DY, Chen L, et al. Presumed asymptomatic carrier transmission of COVID-19. JAMA 2020;323:1406-7.

26. Choi SH, Kim HW, Kang JM, Kim DH, Cho EY. Epidemiology and clinical features of coronavirus disease 2019 in children. Clin Exp Pediatr 2020;63:125-32.

27. Ren SY, Wang WB, Hao YG, Zhang HR, Wang ZC, Chen YL, et al. Stability and infectivity of coronaviruses in inanimate environments. World J Clin Cases 2020;8:1391-9.

28. Public Health Ontario. Synopsis. COVID-19 - What We Know So Far About...Routes of transmission. 28 April 2020. Available at: www.publichealthontario.ca > ncov > covid-wwks (accessed 12 June 2020).

29. World Health Organization. Coronavirus disease 2019 (COVID-19). Situation report - 73. Geneva: WHO, 2 April 2020. Available at: https://www.who.int/emergencies/ diseases/novel-coronavirus-2019/situation-reports/ (accessed 12 June 2020).

30. Public Health Ontario. Synopsis. COVID-19 - What We Know So Far About...The Period of Communicability. 30 March 2020. Available at: www.publichealthontario.ca > ncov > covid-wwks (accessed 12 June 2020).

31. $\mathrm{Wu}, \mathrm{JT}$, Leung $\mathrm{K}$, Leung GM. Nowcasting and forecasting the potential domestic and international spread of the 2019-nCoV outbreak originating in Wuhan, China: a modelling study. Lancet 2020;395:689-97.

32. Sanche S, Lin YT, Xu C, Romero-Severson E, Hengartner N, Ke R. High Contagiousness and Rapid Spread of Severe Acute Respiratory Syndrome Coronavirus 2 [published online ahead of print, $2020 \mathrm{Apr} 71$. Emerg Infect Dis 2020;26(7):10.3201/eid2607.200282. doi:10.3201/ eid2607.200282.

33. Moore KA, Lipsitch M, Barry JM, Osterholm MT. COVID-19: The CIDRAP viewpoint. Part 1 . The future of the COVID-19 pandemic: Lessons learned from pandemic influenza. Report April 30th, 2020. University of Minnesota. Available at: https://www.cidrap.umn.edu/ covid-19/covid-19-cidrap-viewpoint (Accessed 14 June 2020).

34. Guan WJ, Ni ZY, Hu Y, Liang WH, Ou CQ, He JX, et al. Clinical Characteristics of Coronavirus Disease 2019 in China. N Engl J Med 2020;382:1708.

35. Yang X, Yu Y, Xu J, Shu H, Xia Ja, Liu H, et al. 2020. Clinical course and outcomes of critically ill patients with SARSCoV-2 pneumonia in Wuhan, China: a single centred, retrospective, observational study. Lancet Respir Med pii: S2213-2600(20)30079-5.

36. Zhang JJ, Dong X, Cao YY, Yuan YD, Yang YB, Yan YQ et al. Clinical characteristics of 140 patients infected with SARS-CoV-2 in Wuhan, China. Allergy 2020. doi: 10.1111/all.14238.

37. Rodriguez-Morales AJ, Cardona-Ospina JA, Gutiérrez-Ocampo E, Villamizar-Peña R, Holguin-Rivera Y, Escalera-Antezana JP, et al. Clinical, laboratory and imaging features of COVID-19: A systematic review and meta-analysis. Travel Med Infect Dis 2020;101623. doi:10.1016/j.tmaid.2020.101623.

38. Yang J, Zheng Y, Gou X, Pu K, Chen Z, Guo Q et al. Prevalence of comorbidities in the Novel Wuhan Coronavirus (COVID-19) infection: a systematic review and meta-analysis. Int J Infect Dis 2020;94:91-5.

39. NCDHHS: COVID 19 response. People at high risk for severe illness. North Carolina Department of Health and Human Services. Available at: http: www.ncdhhs.gov (accessed 12 June 2020).

40. Yang Y, Peng F, Wang R, Guan K, Jiang T, Xu Guogang, et al. The deadly coronaviruses: The 2003 SARS pandemic and the 2020 novel coronavirus epidemic in China. J Autoimmun 2020;109:102434. doi:10.1016/j. jaut.2020.102434.

41. Lai CC, Liu YH, Wang CY, Wang HY, Hsueh SC, Yen MY, 
et al. Asymptomatic carrier state, acute respiratory disease, and pneumonia due to severe acute respiratory syndrome coronavirus 2 (SARS-CoV-2): Facts and myths. J Microbiol Immunol Infect 2020; doi:10.1016/j. jmii.2020.02.012.

42. Shi H, Han X, Jiang N, Cao Y, Alwalid O, Gu J, et al. Radiological findings from 81 patients with COVID-19 pneumonia in Wuhan, China: a descriptive study. Lancet Infect Dis 2020;20:425.

43. Hamid S, Mir MY, Rohela GK. Novel coronavirus disease (COVID-19): a pandemic (epidemiology, pathogenesis and potential therapeutics). New Microbes New Infect 2020;35:100679. doi:10.1016/j.nmni.2020.100679.

44. WHO Director-General's opening remarks at the media briefing on COVID-19 - 24 February 2020. Available at: https://www.who.int/dg/speeches/detail/who-director-general-s-opening-remarks-at-the-media-briefing-on-covid-19---24-february-2020 (accessed 13 June 2020).

45. European Centre for Disease Prevention and Control. Case definition coronavirus disease 2019 (COVID-19). Available at: www.ecdc.europa.eu > covid-19-pandemic (accessed 13 June 2020).

46. WHO. Clinical management of COVID-19. Interim guidance. 27 May 2020. World Health Organization, 2020 Available at: https://www.who.int/publications/i/ item/clinical-management-of-covid-19 (accesed June 14, 2020).

47. Ahn DG, Shin HJ, Kim MH, Lee S, Kim HS, Myoung J, et al. Current Status of Epidemiology, Diagnosis, Therapeutics, and Vaccines for Novel Coronavirus Disease 2019 (COVID-19). J Microbiol Biotechnol 2020;30:313-24.

48. Stajić M, Maksimović ŽM, Verhaz A. COVID-19 pneumonia: when negative PCR testing does not rule out the disease. Scr Med 2020;51(2):120-3.

49. Sethuraman N, Jeremiah SS, Ryo A. Interpreting Diagnostic Tests for SARS-CoV-2. JAMA. 2020 May 6. doi: 10.1001/jama.2020.8259.

50. Lou B, Li T, Zheng S, Su Y, LiZ, Liu W, et al. Serology characteristics of SARS-CoV-2 infection since the exposure and post symptoms onset. medRxiv. Preprint posted 27 March 2020. doi:10.1101/2020.03.23.20041707.

51. CDC. Coronavirus disease 2019 (COVID-19). Testing for COVID-19. Available at: https://www.cdc.gov/coronavirus/2019-ncov/symptoms-testing/testing.html (accessed 13 June 2020).

52. WHO. "Immunity passports" in the context of COVID-19. 24 April 2020. World Health Organization, 2020. Available at: https://www.who.int/news-room/commentaries/detail/immunity-passports-in-the-context-ofcovid-19 (Accessed 14 June 2020).

53. WHO. Updated WHO advice for international traffic in relation to the outbreak of the novel coronavirus 2019-nCoV. Geneva: WHO, 24 January 2020. Available at: https://www.who.int/ith/2020-24-01-outbreak-ofPneumonia-caused-by-new-coronavirus/en/(accessed 13 June 2020)

54. Mayr V, Nußbaumer-Streit B, Gartlehner G. Quarantäne alleine oder in Kombination mit weiteren Public-HealthMaßnahmen zur Eindämmung der COVID-19 Pandemie: Ein Cochrane Rapid Review [Quarantine Alone or in Combination with Other Public Health Measures to Control COVID-19: A Rapid Review (Review)] [published online ahead of print, 2020 May 15]. Gesundheitswesen. 2020;10.1055/a-1164-6611. doi:10.1055/a-1164-6611

55. Abel T, McQueen D. The COVID-19 pandemic calls for spatial distancing and social closeness: not for social distancing! Int J Public Health 2020;65:231.

56. WHO. Advice on the use of masks in the context of the novel coronavirus (2019-nCoV) outbreak. April 6, 2020. Geneva: WHO. Available at: https://www.who. int/publications-detail/advice-on-the-use-of-masksin-the-community-during-home-care-and-in-healthcare-settings-in-the-context-of-the-novel-coronavirus(2019-ncov)-outbreak (accessed 13 June 2020).

57. Feng S, Shen C, Xia N, Song W, Fan M, Cowling BJ. Rational use of face masks in the COVID-19 pandemic. Lancet Re- spir Med 2020;S2213-2600(20)30134-X. doi:10.1016/ S2213-2600(20)30134-X

58. Centers for Disease Control and Prevention. Public health recommendations for people in U.S. Communities exposed to a person with known or suspected COVID-19, other than health workers or other critical infrastructure workers. Available at: https://www.cdc.gov/coronavirus/2019-ncov/php/public-health-recommendations.html (accessed 13 June 2020).

59. Centers for Disease Control and Prevention. Public health recommendations after travel-associated COVID-19 exposure. Available at: https://www.cdc.gov/coronavirus/2019-ncov/php/risk-assessment.html (accessed 13 June 2020).

60. Palmore T. Coronavirus disease 2019 (COVID-19): Infection control in health care and home settings In: McIntosh K. Coronavirus disease 2019 (COVID-19): Epidemiology, virology, clinical features, diagnosis, and prevention. Available at: https://www.uptodate.com/contents/ coronavirus-disease-2019-covid-19-infection-controlin-health-care-and-home-settings?topicRef $=126981 \&$ source=see_link (accessed 13 June 2020).

61. Kirkcaldy RD, King BA, Brooks JT. COVID-19 and postinfection immunity: limited evidence, many remaining questions. JAMA. Published online 11 May 2020. doi:10.1001/jama.2020.7869.

62. Euronews. Analysis: How close are we to COVID-19 herd immunity? Available at: https://www.euronews. com/2020/05/15/analysis-how-close-are-we-to-covid19-herd-immunity (accessed June 13, 2020).

63. Kwok KO, Lai F, Wei WI, Wong SYS, Tang JWT. Herd immunity - estimating the level required to halt the COVID-19 epidemics in affected countries. J Infect. 2020;80(6):e32-e33. doi:10.1016/j.jinf.2020.03.027

64. Mahase E. Covid-19: What do we know so far about a vaccine? BMJ. 2020;369:m1679. doi:10.1136/bmj.m1679

65. Mitjà 0 , Clotet B. Use of antiviral drugs to reduce COVID-19 transmission. Lancet Glob Health 2020;8(5):e639-e640.

66. World Health Organization. Coronavis disease 2019 (COVID-19). Situation report - 8. Geneva: WHO, 28 January 2020. Available at: https://www.who.int/emergencies/diseases/novel-coronavirus-2019/situation-reports / (accessed 13 June 2020).

67. Zumla A, Hui DS, Azhar EI, Memish ZA, Maeurer M. Reducing mortality from 2019-nCoV: host-directed therapies should be an option. Lancet 2020;395(10224):e35-e36.

68. Centers for Disease Control and Prevention (CDC). Information for clinicians on investigational therapeutics for patients with COVID-19. Available at: https://www. cdc.gov/coronavirus/2019-ncov/hcp/clinical-guidance-management-patients.html (accessed 14 June 2020).

69. Chinese Clinical Guidance for COVID-19 Pneumonia Diagnosis and Treatment (7th edition). Available at: http:// kjfy.meetingchina.org/msite/news/show/cn/3337. html (accessed 14 June 2020).

70. NIH. COVID-19 Treatment Guidelines. What's New in the Guidelines. Available at: https://www.covid19treatmentguidelines.nih.gov/whats-new/ (accessed 13 June 2020).

71. Khan Z, Karatas Y, Rahman H. Anti COVID-19 Drugs: Need for More Clinical Evidence and Global Action [published online ahead of print, $2020 \mathrm{Apr} 29]$. Adv Ther 2020;1-5. doi:10.1007/s12325-020-01351-9

72. Rubin R. Testing an Old Therapy Against a New Disease: Convalescent Plasma for COVID-19. JAMA Published online April 30, 2020. doi:10.1001/jama.2020.7456.

73. Begley S. Three potential futures for Covid-19: recurring small outbreaks, a monster wave, or a persistent crisis. Available at: https://www.statnews.com/2020/05/01/ three-potential-futures-for-covid-19/ (accessed 14 June 2020).

74. Lee A. Wuhan novel coronavirus (COVID-19): why global control is challenging? Public Health 2020;179:A1-A2 doi:10.1016/j.puhe.2020.02.001. 